\title{
Wnt Pathway in Bone Repair and Regeneration - What Do We Know So Far
}

\author{
Khosrow S. Houschyar ${ }^{1 *}$, Christian Tapking ${ }^{2,3}$, Mimi R. Borrelli ${ }^{4}$, Daniel Popp ${ }^{2,5}$, \\ Dominik Duscher 6 , Zeshaan N. Maan ${ }^{4}$, Malcolm P. Chelliah ${ }^{4}$, Jingtao Li ${ }^{7}$, \\ Kamran Harati' ${ }^{1}$, Christoph Wallner ${ }^{1}$, Susanne Rein ${ }^{8}$, Dominik Pförringer ${ }^{9}$, \\ Georg Reumuth ${ }^{10}$, Gerrit Grieb ${ }^{11}$, Sylvain Mouraret ${ }^{4,12}$, Mehran Dadras', \\ Johannes M. Wagner ${ }^{1}$, Jungul Y. Cha ${ }^{13}$, Frank Siemers ${ }^{10}$, Marcus Lehnhardt ${ }^{1}$ and \\ Björn Behr ${ }^{1}$
}

\section{OPEN ACCESS}

Edited by: Darius Widera,

University of Reading,

United Kingdom

Reviewed by:

Gianpaolo Papaccio, Università degli Studi della Campania "Luigi Vanvitelli" Naples, Italy

Claudio Cantù,

Linköping University, Sweden Aaron W. James,

Johns Hopkins University,

United States

*Correspondence:

Khosrow S. Houschyar

Khosrow-Houschyar@gmx.de

Specialty section: This article was submitted to

Stem Cell Research,

a section of the journal

Frontiers in Cell and Developmental

Biology

Received: 05 September 2018

Accepted: 30 November 2018

Published: 07 January 2019

Citation:

Houschyar KS, Tapking C Borrelli MR, Popp D, Duscher D, Maan ZN, Chelliah MP, Li J, Harati K,

Wallner $C$, Rein $S$, Pförringer $D$,

Reumuth G, Grieb G, Mouraret S,

Dadras M, Wagner JM, Cha JY,

Siemers F, Lehnhardt M and Behr B (2019) Wnt Pathway in Bone Repair and Regeneration - What Do We

Know So Far.

Front. Cell Dev. Biol. 6:170.

doi: 10.3389/fcell.2018.00170
1 Department of Plastic Surgery, BG University Hospital Bergmannsheil, Ruhr University Bochum, Bochum, Germany, ${ }^{2}$ Department of Surgery, Shriners Hospital for Children-Galveston, University of Texas Medical Branch, Galveston, TX, United States, ${ }^{3}$ Department of Hand, Plastic and Reconstructive Surgery, Burn Trauma Center, BG Trauma Center Ludwigshafen, University of Heidelberg, Heidelberg, Germany, ${ }^{4}$ Division of Plastic and Reconstructive Surgery, Department of Surgery, Stanford School of Medicine, Stanford, CA, United States, ${ }^{5}$ Division of Hand, Plastic and Reconstructive Surgery, Department of Surgery, Medical University of Graz, Graz, Austria, ${ }^{6}$ Department of Plastic Surgery and Hand Surgery, Technical University Munich, Munich, Germany, ${ }^{7}$ State Key Laboratory of Oral Diseases and Department of Oral Maxillofacial Surgery, West China Hospital of Stomatology, Sichuan University, Chengdu, China, ${ }^{8}$ Department of Plastic and Hand Surgery-Burn Center-Clinic St. Georg, Leipzig, Germany, ${ }^{9}$ Clinic and Policlinic of Trauma Surgery, Klinikum Rechts der Isar, Technical University Munich, Munich, Germany, ${ }^{10}$ Department of Plastic and Hand Surgery, Burn Unit, Trauma Center Bergmannstrost Halle, Halle, Germany, ${ }^{11}$ Department of Plastic Surgery and Hand Surgery, Gemeinschaftskrankenhaus Havelhoehe, Teaching Hospital of the Charité Berlin, Berlin, Germany, ${ }^{12}$ Department of Periodontology, Service of Odontology, Rothschild Hospital, AP-HP, Paris 7 - Denis, Diderot University, U.F.R. of Odontology, Paris, France, ${ }^{13}$ Orthodontic Department, College of Dentistry, Yonsei University, Seoul, South Korea

Wnt signaling plays a central regulatory role across a remarkably diverse range of functions during embryonic development, including those involved in the formation of bone and cartilage. Wht signaling continues to play a critical role in adult osteogenic differentiation of mesenchymal stem cells. Disruptions in this highly-conserved and complex system leads to various pathological conditions, including impaired bone healing, autoimmune diseases and malignant degeneration. For reconstructive surgeons, critically sized skeletal defects represent a major challenge. These are frequently associated with significant morbidity in both the recipient and donor sites. The Wnt pathway is an attractive therapeutic target with the potential to directly modulate stem cells responsible for skeletal tissue regeneration and promote bone growth, suggesting that Wnt factors could be used to promote bone healing after trauma. This review summarizes our current understanding of the essential role of the Wnt pathway in bone regeneration and repair.

Keywords: Wnt, $\beta$-catenin, canonical, non-canonical, regeneration, repair, stem cells, bone

\section{INTRODUCTION}

Unlike most tissues in the human body, bone is capable of spontaneous scarless repair throughout adult life. Skeletal tissue heals following injury by producing new bone with structural geometry and biomechanical integrity (Tarantino et al., 2011) indistinguishable from the surrounding bone (Arvidson et al., 2011). The process of fracture healing in the adult skeleton recapitulates embryonic 
bone development and is considered a form of tissue regeneration (Ferguson et al., 1999). It is a complicated metabolic process, involving certain regenerative patterns and changes in the expression of 1000s of genes (Marsell and Einhorn, 2011). Disruption to this highly coordinated process can result in delayed or impaired healing (Victoria et al., 2009) leading to mal-union or 'Non-union.' Numerous pre-, intra-, and post-operative factors have been found to be associated with impaired bone healing (Panteli et al., 2015), including excessive periosteal stripping, damage to surrounding soft tissue, inadequate post-traumatic or post-operative immobilization, repeated manipulations, and excessive early motion at fracture sites (Victoria et al., 2009). The exact molecular mechanisms of delayed fracture healing, however, are unknown.

Fracture repair is regulated by multiple growth factors (Lieberman et al., 2002). The Wnt signaling pathway has well-known and central roles in bone development, homeostasis, as well as bone repair and regeneration following injury (Xu et al., 2014). Wnt ligands stimulate bone growth, suggesting a strong regulatory role for canonical Wnt signaling pathway in bone healing and highlighting its potential as a therapeutic target to augment fracture healing. A number of molecules able to enhance the canonical Wnt signaling have shown promise in pre-clinical and clinical trials (Secreto et al., 2009).

In this paper we review the canonical Wnt signaling pathway and its role in bone regeneration and repair. A provide an overview of the Wnt pathway and discuss specific canonical Wnt-signaling molecules that may offer favorable targets for facilitating bone repair and regeneration.

\section{FORMATION OF BONE DURING EMBRYOLOGICAL DEVELOPMENT}

In the early stages of embryonic development, the skeleton is composed of fibrous membrane and hyaline cartilage (Wang M. et al., 2017). By the sixth or seventh week of embryonic life ossification (osteogenesis), begins (Rivas and Shapiro, 2002). Skeletogenesis involves the combined action of numerous genetic programs governing vasculogenesis (Ingber and Levin, 2007), and the specification, proliferation, differentiation, programmed cell death, and remodeling of the ECM. These processes are underpinned by key molecular pivots (Table 1), and as the molecular orchestra responsible for bone formation in the fetus also plays a role in adult skeletal repair (Gadjanski et al., 2012), these pivots represent potential therapeutic targets (Table 2).

Together, bone and cartilage comprise skeleton, and are produced by osteoblasts and chondrocytes, respectively (Regard et al., 2012). During embryological development, bone is formed by (1) intramembranous and (2) endochondral ossification (Figure 1A). During embryonic development skeletal elements are separate in places to form joints, critical structures for mobility. Synovial allow for movement between boney fronts, and form upon the dedifferentiation and flattening of chondrogenic cells in newly formed cartilage, which creates an interzone (Figure 1B).

\section{MECHANISMS OF BONE REPAIR AND REGENERATION}

The main function of the skeleton is structural; it creates a strong, protective, mechanically optimal structure for more delicate organs and soft tissues (Oryan et al., 2015). Bone tissue constantly adapts to biomechanical loading and environmental stress (Ozcivici et al., 2010) through two opposing but synergistic processes; bone resorption and bone formation (Feng and McDonald, 2011).

Bone repair following damage is a complex and well-organized regenerative process initiated in response to injury which effectively restores skeletal function (Morgan et al., 2014). Unlike other adult tissues, which generate scar tissue in response to injury, the skeleton undergoes regenerative healing, forming new bone indistinguishable from adjacent, uninjured tissue (Colnot et al., 2003). Fracture healing mimics early developmental processes and occurs by both direct and indirect repair (Secreto et al., 2009). Direct (primary) repair is possibly when the bony fronts of adjacent bones are in close contact. This is usually the case after surgical treatment with stable fixation of the injury (Pesce et al., 2009). Osteoprogenitor cells, osteoclasts, and undifferentiated mesenchymal stem/stromal cells (MSCs) recruited to the fracture site may also promote bone formation in a mechanism similar to formation of bone during intramembranous ossification in the skull and clavicles (Wu et al., 2016). During indirect (secondary) healing, bone formation is akin to endochondral ossification, the developmental method by which long bones are originally made in development (Long and Ornitz, 2013). Following injury, a soft callus forms composed of largely inflammatory cells. This callus develops into an intermediate cartilaginous template which subsequently undergoes calcification, and ultimately is replaced by woven bone (Marsell and Einhorn, 2011) and then lamellar bone through a remodeling process that takes several months before. The resulting lamellar bone is able to support normal load bearing (Marsell and Einhorn, 2011). With surgical fixation, temporary immobilization, or both, most fractures heal after several months. However, three to $10 \%$ of fractures fail to heal and result in the formation of a fibrous or non-union (Kloen et al., 2012). The rate of successful fracture healing may be increased, and the time of healing decreased, by therapies that induce bone formation at the break point (Hoang-Kim et al., 2009).

\section{Three Wnt Signaling Pathways}

Wnt signaling is a pathway that has been conserved over evolution. It regulates important aspects of cell polarity, cell fate determination, cell migration, formation of the primary axis, organogenesis, and the renewal of stem cells during embryonic development (Komiya and Habas, 2008). Dysregulation of Wnt signaling has been implicated in many diseases, including autoimmune diseases and cancer (Shi et al., 2016).

The name Wnt originates from the fusion of wingless, the segment polarity gene of the Drosophila, and integrated (int-1), the vertebrate homolog (van Amerongen and Nusse, 2009). Wnt ligands, which are encoded by 19 Wnt genes, 
TABLE 1 | Key molecules and cells involved in bone repair.

\section{Key factors Function}

\section{Extracellular messengers}

\section{IL-1, IL6, TNF $\alpha$}

TGF $\beta$

BMP2

BMP4

BMP7

SDF1

Noggin

FGFb

|GF-I, ||

PIGF

VEGF

PDGF

Wnts

DKK1

Ihh

PTHrP

OPG

RANKL

M-CSF

Gastrointestinal serotonin

\section{Intracellular messengers}

PKA/CREB

MAPKs

$\beta$-Catenin

Runx2

Osterix

DIx5

Msx2

$N F-k B$

Cells

MSCs

Osteoblasts

Adipose tissue-derived stromal cells
Elicit inflammation and migration

Mitogenic factor, osteogenic factor

Osteogenic factor

Osteogenic factor

Osteogenic factor

Chemotactic factor

BMP2, 4, and 7 specific inhibitor

Angiogenic and mitogenic factor, osteogenic factor (controversial)

Mitogenic factors, osteogenic factors

Angiogenic and vasculogenic factor

Angiogenic and vasculogenic factor

Mitogenic and chemotactic factor

Mitogenic and osteogenic factors

Inhibitor of Wnt signaling

Osteochondrogenic factor

Osteochondrogenic factor

Decoy receptor of RANKL, inhibition of RANKL

Induces osteoclastogenesis

Induces osteoclastogenesis

Neurotransmitter inhibiting osteogenesis

Transduce osteogenic signaling

Transduce osteogenic signaling by phosphorylation

Osteogenic transducer factor

Early osteogenic transcription factor

Late osteogenic transcription factor

Osteogenic homeobox protein

Osteogenic homeobox protein

Inflammation transducer factor, inhibits osteogenesis

Origin of osteoblasts

Osteogenic professional cells

Multipotential cells
In vivo and in vitro effects

In vitro inhibit osteoblastic differentiation, but in vivo TNF $\alpha$ is crucial for bone repair; role of IL-6 is controversial (anti-or pro-osteogenic probably, depending on soluble IL-6 receptor)

Can induce osteoblast differentiation at the early stage of immature cells but can also inhibit osteogenesis in committed cells

Osteochondrogenic factor; might initiate bone formation and bone healing and can induce expression of other BMPs

Osteochondrogenic factor in vivo and in vitro

Osteogenic factor in vivo and in vitro; active on more mature osteoblasts

Allows MSCs homing both in vitro and in vivo

Suppresses osteoblastic differentiation

Mutations induce chondrodysplasia and craniosynostosis; can stimulate Sox9; might be a negative regulator of postnatal

Stimulates growth plate formation, endochondrate ossification and bone formation by osteoblasts

Induces proliferation and osteogenic differentiation of MSCs; crucial for vascularization

Most potent angiogenic and vasculogenic factor; crucial at the onset of bone formation

Highly mitogenic factor for MSCs and chemotactic for MSCs, osteoblasts and perivascular cells

Depending on Wnt type, crucial for osteoprogenitor proliferation; can also inhibit final osteoblast maturation

Strongly inhibits osteogenesis of MSC and osteoprogenitor cells; can stimulate terminal maturation

Pivotal role for growth plate and endochondral formation; can inhibit osteoblast differentiation; might induce PTHrP expression

Pivotal role for growth plate and endochondral formation; can induce or inhibit osteogenesis

Strongly inhibits bone resorption and has a pivotal role in bone remodeling

Strongly stimulates bone resorption and has a pivotal role in bone remodeling

Crucial for osteoclastogenesis

Expressed by enterochromatin cells, inhibits bone formation and repressed by Lrp5

Can transduce osteogenic signaling (still controversial); possible indirect effect

Crucial for regulation of intracellular signaling induced by osteogenic factors (still controversial)

Pivotal role in transducing osteogenic signal from Wnt and is negatively regulated by GSK3 $\beta$

Master regulator of early osteogenesis; runx2 mice died, with no bone formation

Master regulator of late osteogenesis, inhibiting chondrogenesis Induces osteoblast maturation but inhibits osteocyte formation Induces proliferation of immature cells; responses depend on Dlx5 quantity

Inhibits the differentiation of MSCs and committed osteoblastic cells

Can form bone in vivo and osteoblasts in vitro

Generate bone formation

Can give rise to bone in vivo and in vitro but are less effective than bone marrow MSCsl 
TABLE 2 | Clinical relevance of key factors in bone repair.

\begin{tabular}{|c|c|}
\hline Key factors tested & Observations \\
\hline BMP2 & $\begin{array}{l}\text { Used for spine fusion, bone non-union and bone } \\
\text { defects; clinically efficient for bone repair and } \\
\text { regeneration; some adverse effects observed } \\
\text { (osteolysis and ectopic bone formation) }\end{array}$ \\
\hline BMP7 & $\begin{array}{l}\text { Used for spine fusion and bone non-union; clinically } \\
\text { efficient for bone repair }\end{array}$ \\
\hline PTHrP/PTH & $\begin{array}{l}\text { Used for osteoporosis; efficient for increasing bone } \\
\text { mass when intermittently administered }\end{array}$ \\
\hline Wnt- $\beta$-catenin & $\begin{array}{l}\mathrm{LiCl} \text { used as a specific inhibitor of GSK3 } \beta \text { to } \\
\text { increase bone mass post-fracture and to diminish } \\
\text { fracture risk Bortezomib, proteasome inhibitor used } \\
\text { in treatment of multiple myeloma (MM); also } \\
\text { increases bone mass Anti-DKK1 monoclonal } \\
\text { antibody (BHQ880) used to inhibit osteolysis in MM } \\
\text { or to increase BMD Anti-sclerostin antibody used to } \\
\text { increase bone mass }\end{array}$ \\
\hline RANKL/OPG & $\begin{array}{l}\text { Targeting RANKL to treat osteoporosis; e.g., } \\
\text { denosumab (anti-RANKL antibody), which can be } \\
\text { used with biphosphonates }\end{array}$ \\
\hline Biphosphonates & $\begin{array}{l}\text { Widely used for osteoporosis, bone necrosis, } \\
\text { osteogenesis imperfecta and some osteolytic } \\
\text { tumors (MM) (zoledronate, alendronate, } \\
\text { risedronate); some adverse effects noted } \\
\text { (osteonecrosis, inhibition of osteogenesis) }\end{array}$ \\
\hline TGF $\beta$ & Used as a bone non-union marker \\
\hline Platelet-rich plasma & $\begin{array}{l}\text { Used in maxillofacial surgery and for bone defects } \\
\text { with or without biomaterials with or without } \\
\text { osteoregenerative cells }\end{array}$ \\
\hline MSCs or osteoblasts & $\begin{array}{l}\text { In vitro-expanded MSCs (or osteoblasts) used for } \\
\text { bone defects, osteonecrosis, immune rejection; } \\
\text { randomized controlled clinical trials are required }\end{array}$ \\
\hline
\end{tabular}

are cysteine rich highly hydrophobic proteins, 320-400 amino acid base pair in length, with an N-terminal signal peptide for secretion, and a high degree of sequence homology (Wang et al., 2018). The Wnt ligands bind receptors on the cell surface of recipient cells to activate the Wnt pathway by triggering intracellular signaling cascades which orchestrate numerous cell biological and developmental processes (Willert and Nusse, 2012), important in many physiological settings (MacDonald et al., 2009). Due to thier hydrophobic natuextrre, Wnt proteins are found in association with cell membranes and the ECM. They become palmitoylated in the endoplasmic reticulum of Wnt-producing cells in the presence of acyltransferase porcupine (Herr and Basler, 2012). This palmitate modification is thought to assist in ligand reception on Wnt-responding cells (Mikels and Nusse, 2006). Modified Wnt proteins are then transported and secreted in secretory vesicles which are under control by Wntless/Evi (evenness interrupted) - the multi-pass transmembrane protein present in the plasma membrane and/or the Golgi apparatus (Ching and Nusse, 2006). This facilitates the release of Wnt protein from the cells and thus their association with the seven-pass transmembrane receptor Frizzled (Fzd) (Maupin et al., 2013). Fzd is present on the surface of responding cells and possesses a large extracellular domain, the 'cysteine-rich domain' - made of 10 cysteine residues in a conserved motif'(Huang and Klein, 2004). Low-density lipoprotein receptor-related proteins 5 or $6(\mathrm{LRP} 5 / 6)$ or ROR act as co-receptors to Fzd and assist the binding between Wnt proteins and the receptor (MacDonald and He, 2012). The co-receptor engaged then determines the downstream effect of the successful ligand binding, initiating either the non-canonical or the canonical pathways (Mohammed et al., 2016). As the Wnt signaling pathway is fundamental during embryological development, the expression of Wnt proteins and antagonists happens under strict temporal and spatial regulation (Komiya and Habas, 2008).

Intracellular Wnt signaling is categorized into least three main pathways: (1) the $\beta$-catenin dependent pathway (also called the 'canonical Wnt pathway'); (2) the planar cell polarity (PCP) pathway; and 3 . the $\mathrm{Wnt} / \mathrm{Ca}^{2+}$ pathway (Houschyar et al., 2015). In the canonical Wnt signaling pathway, the ubiquitination and degradation of $\beta$-catenin mediated by glycogen synthase kinase 3 (GSK-3) is inhibited (Gao et al., 2014). In the PCP pathway, Wnt signaling activates jun N-terminal kinase (JNK) and this results in cytoskeletal rearrangements into an asymmetrical organization, as well as polarization of cell morphology within the plane of epithelial sheets (Geetha-Loganathan et al., 2008). This pathway shares many components of the canonical Wnt pathway including Frizzled, and the downstream components GTPase Rho and a kinase cascade including Misshapen, JNK kinase, and JNK (Habas and Dawid, 2005). GSK-3 and adenomatous polymosis coli (APC) of the canonical Wnt signaling pathway are also involved in spindle orientation and asymmetric cell division of C. elegans and Drosophila (Wu and Herman, 2006). In the $\mathrm{Wnt} / \mathrm{Ca}^{2+}$ pathway, Wnt is involved in the release of intracellular calcium, possibly via $\mathrm{G}$ proteins ( $\mathrm{Lu}$ and Carson, 2009; Thrasivoulou et al., 2013). This pathway includes activation of Phospholipase C (PLC), protein kinase C (PKC), and calmodulin-dependent kinase II, and has a role in Xenopus ventralization and in the regulation of convergent extension movements (Kestler and Kuhl, 2008). The canonical Wnt signaling pathway is the best characterized and is strongly implicated in skeletal tissue regeneration and repair (Clevers, 2006) (Figure 2).

\section{CANONICAL Wnt SIGNALING PATHWAY}

Recent investigation into the canonical Wnt pathway has led to novel insights into the various levels of canonical Wnt signaling whichhave refined the model of how this pathway is regulated (Zhan et al., 2017). At least seven of $19 \mathrm{Wnt}$ proteins (Wnts 1, 2, 3a, 3b, 4, 8, and 10b), can activate this pathway (Chen et al., 2015). Cannonical Wnt signaling results in the accumulation and translocation of Beta-catenin ( $\beta$-catenin), into the nucleus (Enzo et al., 2015). $\beta$-catenin is an adherens junction-associated protein and functions to: (1) enable cell-cell adhesion; and (2) mediate intracellular Wnt signaling (Valenta et al., 2012). Intranuclear accumulation of $\beta$-catenin activates transcription factors that target specific genes that mediate cellular development (Cadigan and Waterman, 2012). Dysregulation of $\beta$-catenin signaling is implicated in a number of malignancies, suggesting its important 


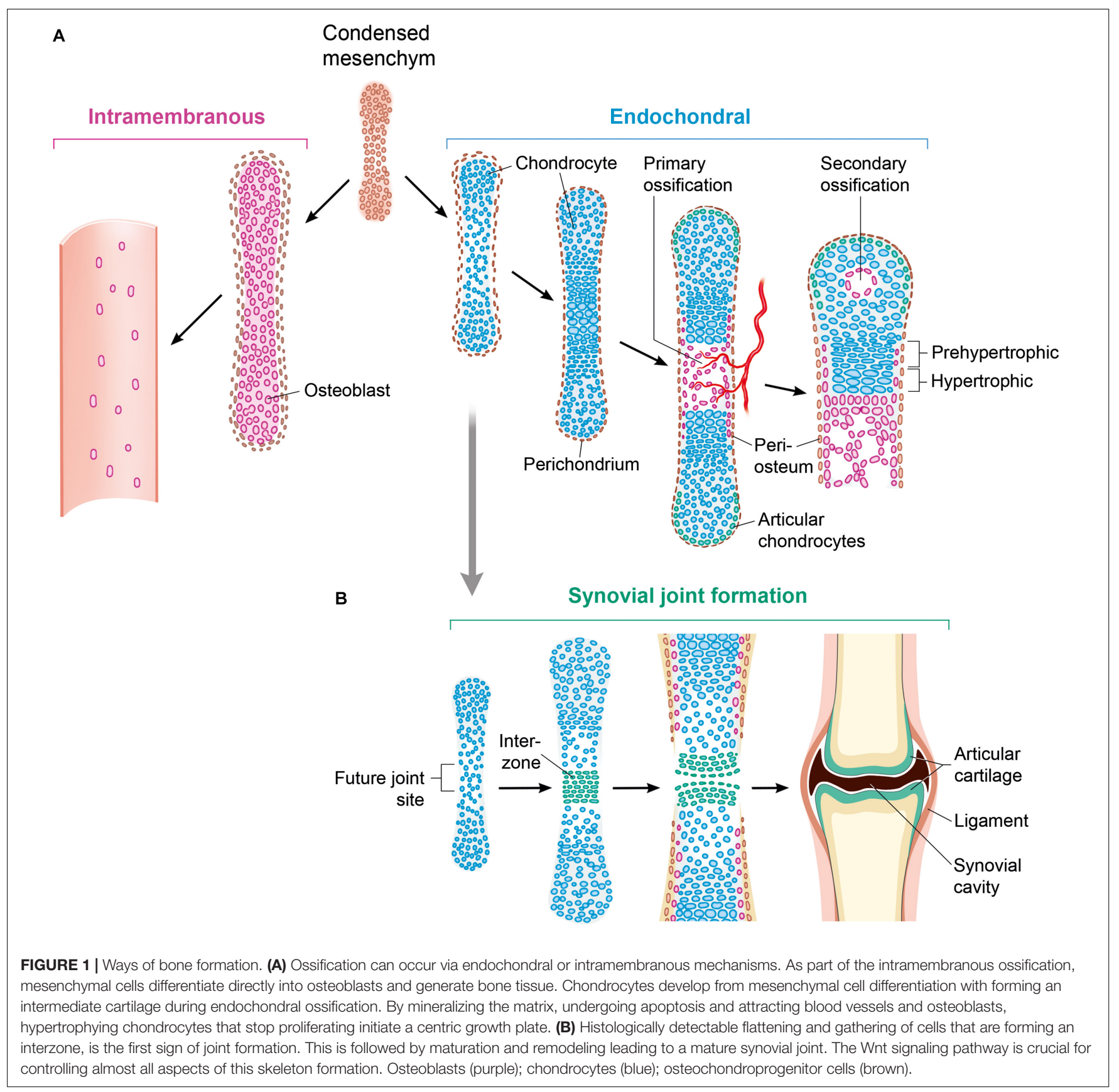

role in the control of cellular proliferation and/or cell death (Tarapore et al., 2012). In the absence of Wnt ligands, cytoplasmic $\beta$-catenin is degraded by a multiprotein complex made of Axin, casein kinase 1 (CK1), APC and GSK3 (Stamos and Weis, 2013). CK1 and GSK3 phosphorylate $\beta$-catenin in the NH2-terminal degradation box, targeting it for ubiquitination (Stamos and Weis, 2013). bTRCP1 (a component of ubiquitin E3 ligase) or bTRCP2 complex the ubiquinate phosphorylated $\beta$-catenin for proteasome-mediated degradation by the $\beta$-catenin destruction complex (Reischl et al., 2007).

The canonical Wnt pathway is activated by binding of specific Wnt ligands to the Fzs along with the LRP-5/6 co-receptors
(Gao et al., 2014). However, Wnt intracellular signaling is complex (Sethi and Vidal-Puig, 2010); there are 10 known human Fz receptors to date (Shevtsov et al., 2006), and although the role of $\mathrm{Fz}$ in acting as a receptor for Wnts has long been known, the role of LRP-5 and its homolog LRP-6, acting as co-receptors for Wnt proteins has only recently been established (MacDonald and He, 2012). The Dickkopf (Dkk) family are secreted proteins which bind LRP-5 or LRP-6 with high affinity can therefore directly antagonize canonical Wnt binding (MacDonald and He, 2012). Upon the successful binding of Wnt with its receptors, the intracellular protein, Dvl, is activated. Dvl transduces the membrane signal from the receptor complex 

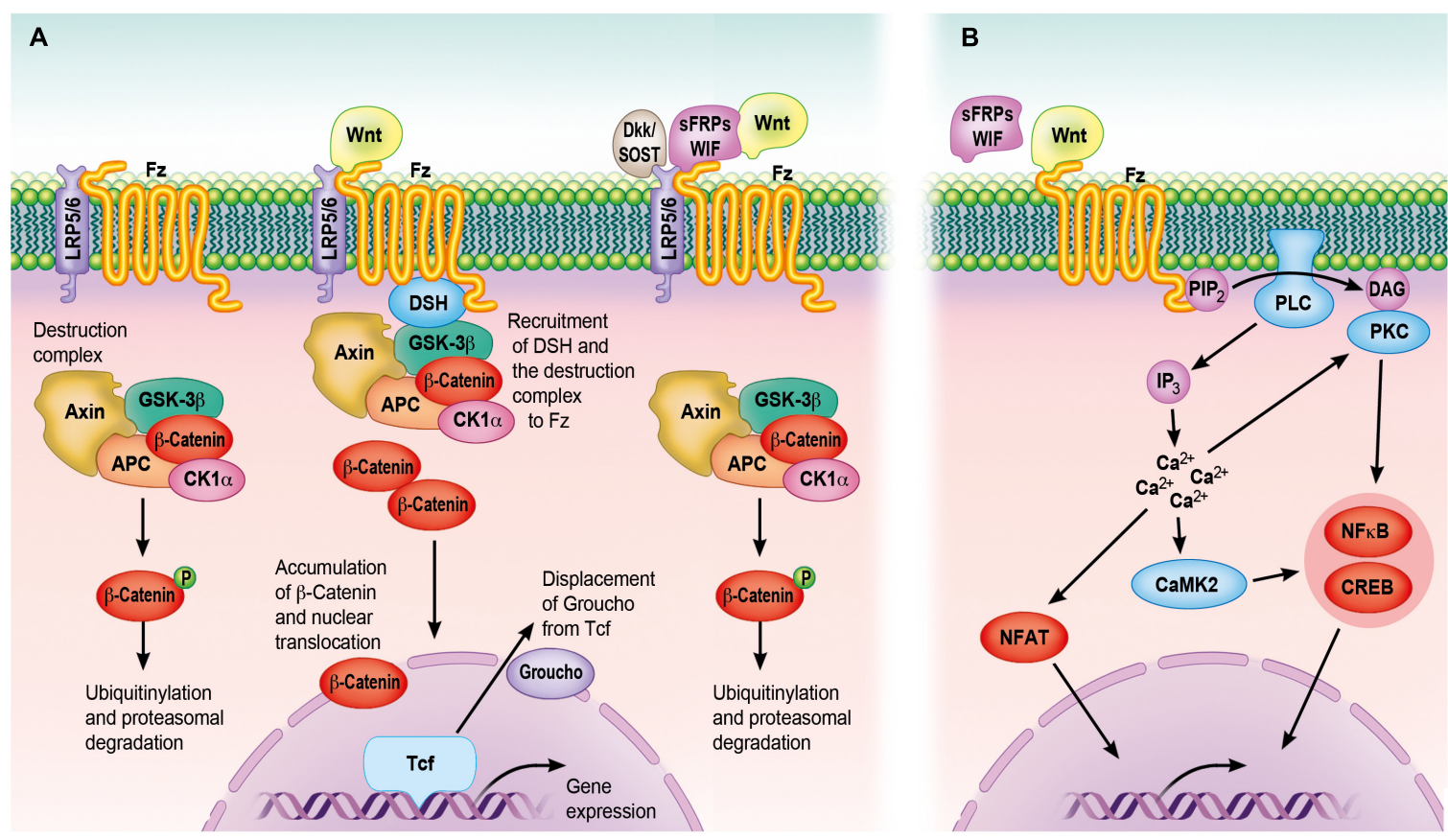

FIGURE 2 | The Wnt signaling cascades. (A) The canonical Wnt signaling cascade depends on $\beta$-catenin, which serves as an intracellular signaling molecule. In case Wnt is not binding to Fz receptors, $\beta$-catenin is sequestered into a destruction complex composed of Axin, CK1 $\alpha$, APC and GSK3 $\beta$, phosphorylated, ubiquitinylated and subsequently degraded by the proteasome. Following the binding of Wnt to Fz receptors and LRP5/6 co-receptors, DSH recruits the destruction complex to the cell membrane by interacting with the receptor complex. This allows newly synthesized $\beta$-catenin to accumulate within the cytoplasm and to translocate to the nucleus. By displacing the transcriptional co-repressor groucho from TCF transcription factors, nuclear $\beta$-catenin can activate a gene transcription program, whereas Wnt-binding antagonists (sFRPs/WIF) and Wnt receptor antagonists (Dkk/SOST) inhibit the canonical cascade. (B) The non-canonical Wnt signaling cascade is characterized by the activation through phosphorylation cascades, which are themselves activated by specific ligand-receptor interactions, seemingly without engagement of the LRP co-receptors. Increasing intracellular $\mathrm{Ca}^{2+}$ levels following PLC- and DAG production can trigger many of these cascades. Subsequently, PKC and CaMKII can activate transcription factors like NFKB and CREB, mediated IP3 and calmodulin is involved in the activation of NFAT. However, only the Wnt-binding antagonists are able to inhibit the non-canonical cascade. APC, adenomatous polyposis coli; CaMKII, calcium/calmodulin-dependent protein kinase type II; CK1 $\alpha$, caseine kinase 1- $\alpha$; CREB, cyclic AMP-responsive element-binding protein; DAG, diacylglycerol; Dkk, Dickkopf; DSH, disheveled; GSK3 $\beta$, glycogen synthase kinase-3 $\beta$; IP3, inositol 1,4,5-triphosphate; LRP, low-density lipoprotein receptor-related protein; NFAT, nuclear factor of activated T cells; NFкB, nuclear factor кB; PIP2, phosphatidylinositol 4,5-bisphosphate; PKC, protein kinase C; PLC, phospholipase C; sFRPs, secreted frizzled-related proteins; SOST, sclerostin; WIF, Wnt inhibitory factor.

(Gonzalez-Sancho et al., 2004) by inhibiting GSK-3b, leading to the collapse of the multi-protein $\beta$-catenin destruction complex (Medina and Wandosell, 2011). Consequently, $\beta$-catenin is not phosphorylated and targeted for proteasome mediated degradation and is able to accumulate in the cytoplasm and translocate to the nucleus. Intranuclear $\beta$-catenin then associates with members of the $\mathrm{T}$ cell factor/lymphoid enhancer factor (TCF/LEF) family and together they activate the transcription of numerous genes involved in a range of functions, for example c-myc and cyclin D1 (Ma and Hottiger, 2016).

The first indication of a link between bone biology and canonical Wnt signaling was discovered more than one decade ago (Baron and Kneissel, 2013). Mutations in the Wnt signaling cascade were found to result in excessive bone growth or in excessive resorption (Yavropoulou and Yovos, 2007): loss of function mutations of the co-receptor LRP5 causes syndromes characterized by low bone mass and consequently frequent bone fractures (Pinzone et al., 2009); alternatively, the gain of function mutations of LRP5 receptor lead to high bone mass (Balemans and Van Hul, 2007). These findings are further corroborated by the association of SNPs of the LRP5 gene with reduced bone mineral density (BMD) and an elevated risk of osteoporotic fractures (Schulze et al., 2010). LRP5 and LRP6 also transduce Wnt signaling in vitro and indicated overlapping roles during in vivo skeletal patterning (Cui et al., 2011). Although LRP5/6 regulate bone mass, the mechanism by which they do so is yet to be fully elucidated.

Recent research shows that that gene variation in Wnt-16 has also been linked with decreased BMD and osteoporotic fractures; Wnt-16 knockout mice have a substantial decrease in bone thickness (Zheng et al., 2012). The initial phase of skeletal tissue repair or active bone remodeling is similar to that occurring during skeletal embryogenesis as skeletal stem cells are shuttled to either the osteogenic or the chondrogenic route (Bianco and Robey, 2015). One study reporting on the Wnt involvement in fracture repair identified upregulation of Wnt5A, $\beta$-catenin, FZD, and numerous target genes following injury (Komatsu et al., 2010). A later follow-up study demonstrated upregulation of additional Wnt related markers such as Wnt5B, LRP5, Disheveled (Dvl), TCF1 and peroxisome proliferator-activated receptor delta 
(PPARD) (Tamura et al., 2010). In contrast, the transcription factor LEF1 was repressed during the initial phases of bone repair, and the stage at which maximal bone was formed (Shahi et al., 2017). However, LEF1 inhibits RUNX2-dependent activation of OCN in osteoblasts. RUNX2 is the transcription factor needed for development of the osteoblast. This suggests that decreased LEF1 expression is necessary for bone repair to occur (Rahman et al., 2015). As described above, $\beta$-catenin has various roles at different stages of bone repair. In the early phases following injury, $\beta$-catenin regulates the ratio of osteoblasts and chondrocytes present in the callus which arises from pluripotent MSCs (Bao et al., 2017). Later in the bone healing process, $\beta$-catenin induces differentiation of osteoblasts and osteoblastic matrix production (Wang T. et al., 2017). LRP5 and $\beta$-catenin gene expression is upregulated in cells present in the fracture callus. $\beta$-catenin is also expressed in proliferating periosteal osteoprogenitor cells, chondrocytes, as well as osteoblasts, which suggests the canonical Wnt signaling pathway is active in both endochondral and intramembranous ossification (Komatsu et al., 2010; Lin and Hankenson, 2011; Regard et al., 2012). Recent work has corroborated this hypothesis; fractured long bones of LRP5 knockout mice are reduced in size, have decreased BMD, and are biomechanically inferior to the long bones of wild-type (WT) littermates (Komatsu et al., 2010). Furthermore, administration of the Wnt antagonist, DKK1 antibody increased the size of the fractured tissue, as well as its BMD and biomechanical properties. This illustrates how ablation of the Wnt-LRP5 interaction delays the reestablishment of biomechanical integrity during bone repair, and that the canonical Wnt pathway, and specifically the LRP5 coreceptor, are key components of fracture repair.

The non-canonical Wnt pathways also contribute to intramembraneous and endochondral ossification following fracture (Heilmann et al., 2013). Wnt-5a is a non-canonical Wnt ligand and has been found to play an integral role in BMP2-mediated osteogenic differentiation (Nemoto et al., 2012). During osteogenic differentiation, BMPs act to downregulate Wnt signaling via sclerostin and Dkk-1 (Kamiya et al., 2008; Zhang et al., 2016b). Absence of the BMP receptor type 1 in osteoblasts of mice results in decreased levels sclerostin and Dkk-1 and increased bone mass (Kamiya et al., 2008). The Wnt-antagonizing effects of BMP led to the suggestion that Smad1 forms a complex with, and thus sequesters, Dvl (Liu et al., 2006). However, understanding the balanced interplay between the BMPs and Wnt ligands are still under intense investigation.

Activation of the Notch pathway inhibits Wnt/ $\beta$-catenininduced osteogenic differentiation (Cao et al., 2017). Overexpression of the Notch intracellular domain, both in vivo and in vitro, is associated with reduced Wnt signaling and impaired osteoblastogenesi (Lin and Hankenson, 2011). The Hedgehog ( $\mathrm{Hh}$ ) works upstream of the Wnt pathway sequentially and promote the osteogenic differentiation of MSCs (James, 2013), and is thus proposed to regulate the early stages of osteogenic differentiation of MSCs (Beederman et al., 2013). Inhibition of Wnt signaling reduces $\mathrm{Hh}$-induced osteogenic activity in both in vitro and in vivo models (Huang et al., 2007).

Wnt signaling is also involved in osteoimmunomodulatory pathways. Of note, tumor necrosis factor (TNF)- $\alpha$ promotes the activity Dkk-1 and thus block osteoblast differentiation (Diarra et al., 2007). Mice overexpressing TNF $\alpha$ have a rheumatoid arthritis-like destruction of their joints (Baum and Gravallese, 2014). Antibody mediated Dkk-1 neutralization in the TNF $\alpha$ transgenic mice rescues the joint destruction and even results in the formation of osteophytes (Diarra et al., 2007). The balance between skeletal bone formation and resorption and the interaction between the Wnt pathway and TNFa-induced inflammatory process, is complex.

There is increasing evidence of crosstalk between the Wnt pathway and other signaling pathways. For example, Wnt pathways reciprocally regulate the progranulin growth factor in frontotemporal dementia (Rosen et al., 2011). Progranulin, or 'proepithelin', is a newly identified growth factors able to promote the differentiation of MSCs into chondrocytes as well as endochondral ossification (Wu et al., 2011). The interplay between Wnts and progranulin in osteogenesis are a subject of future investigations.

Wnt signaling found to induce osteogenic differentiation via changing MicroRNA (miRNA) (Kureel et al., 2018). A number of different miRNA molecules can promote or inhibit MSC mediated osteogenic differentiation (Kang and Hata, 2015). miRNA function to interact with several growth factors and transcriptional factors such as Runx2 and osterix, at various stages of osteogenic differentiation (Vimalraj and Selvamurugan, 2013). Several miRNAs specifically interact with Wnt ligands, with a consequent effect on osteogenesis (Peng et al., 2016); miR-27 inhibits APC, and thus canonical Wnt signaling and promotes bone formation (Wang and Xu, 2010), and miR-335-5p downregulates Dkk-1 and thus promotes osteogenic differentiation (Zhang et al., 2017).

\section{MESENCHYMAL STEM/STROMAL CELLS (MSCs) and Wnt SIGNALING IN BONE DEVELOPMENT AND HOMEOSTASIS}

Mesenchymal stem/stromal cells are multipotent progenitor cells with that ability to into multiple tissue types, including bone, cartilage, fat, tendon, and muscle (Klimczak and Kozlowska, 2016). MSC fate and self-renewing potential, transient amplifying activity is under the influence of the MSC microenvironment and systemic factors (Crane and Cao, 2014). MSCs populate various anatomical locations including the bone marrow and fat, and their impressive differentiation capacity makes them a favorable therapeutic option (Chanda et al., 2010). The ability to promote osteogenic differentiation of MSCs, either prior or post-transplantation, may serve as an effective therapy to promote bone formation in areas of deficiency (Wagner et al., 2011). In the 1960s and 1970s, Friedenstein et al. (1970) were first to describe the rare population $(\sim 0.0001 \%)$ of nucleated cells in the bone marrow which adhere to plastic, form cells of spindle-shaped morphology, and rise to round-shaped fibroblastoid colonies (colony-forming unit-fibroblasts or 'CFU-Fs'). Freidenstein (1990) also demonstrated that the 
bone marrow derived cells have the capacity to differentiate into bone, cartilage, and/or adipose tissue upon in vivo transplantation.

The commitment of MSCs down a certain cell lineage is under the control of a collection of growth factors, but current understanding of the processes influencing cell fates is limited ( $\mathrm{Li}$ et al., 2011). Studies in both mice and humans show that MSCs can augment bone regeneration by differentiating into osteoblasts as well as by secreting osteogenic growth factors and anti-inflammatory cytokines (Zwingenberger et al., 2013). Granero-Moltó et al. (2009) transduced MSCs to express firefly luciferase and show that MSCs migrate toward the fracture site via the CXCR4 receptor and then promote healing by increasing the cartilage and bone content of the callus, thus altering its biomechanical properties. A clinical study reported on the bone-healing effects of MSCs when used as treatment of defects of long bones, with beneficial effects still evident 7-years later (Gjerde et al., 2018). Another clinical study demonstrated the beneficial effects on injecting MSCs along with bisphosphonates to treat femoral head core decompression and avascular necrosis (Gianakos et al., 2016). Injection of an antagonists against the chemokine CC receptor (CCR1) reveals that this receptors is an important chemoreceptor directing MSC migration and osteoblastic differentiation (Gibon et al., 2012). Osteoporosis is a systemic bone disease largely affecting the elderly population. Glucocorticoid-induced osteoporosis in rats can be prevented through systemic administration of allogenic MSCs via their osteoblastogenic effects. Together these data suggest MSCs undergo osteoblastic differentiation and promote a more regenerative inflammatory state, and this may have therapeutic implications for a number of diseases of the bone (Pajarinen et al., 2017).

Wnt signaling pathway has a well-established critical role in promoting osteogenic differentiation of MSCs (Liang et al., 2016). Additionally, Wnt ligands stimulate osteoblast proliferation and support osteoblast maturation (Figure 3). The Wnt signaling pathway is involved in both intramembranous and endochondral ossification (Zhong et al., 2014). Minear et al. (2010) used a mouse model to demonstrate that enhanced Wnt signaling through the delivery of liposomal vesicles containing purified Wnt-3a protein resulted in accelerated fracture healing due to increased proliferation and earlier differentiation of skeletal stem cells/progenitor cells. This highlights the therapeutic potential of using a biochemical strategy through which proteins can be used to deliver Wnt ligands, and thus to increase the duration and strength of the bone healing effect of Wnt signaling. Previously it has been shown that $\beta$-catenin can promote the progression of MSCs from osteoblastic precursor cells into more mature osteoblasts and can also suppress the differentiation of MSCs into adipogenic and chondrogenic lineages (Case and Rubin, 2010; Ullah et al., 2015). The canonical Wnt pathway is especially influential in inhibiting the expression of the major adipogenic inducers, PPAR $\gamma$ and CCAAT/enhancer binding protein $\alpha$, to suppress adipogenic differentiation while upregulating the osteogenic regulators Runx2, Dlx5, and Osterix (Kang et al., 2007). In addition, non-canonical Wnt signaling also induces osteogenic differentiation through a different mechanism (Arnsdorf et al., 2009). The non-canonical ligand Wnt-5a suppresses PPAR $\gamma$ (Topol et al., 2003) and thus inactivates chromatins. Although the interplay between these two independent mechanisms induced by Wnt ligands is still not

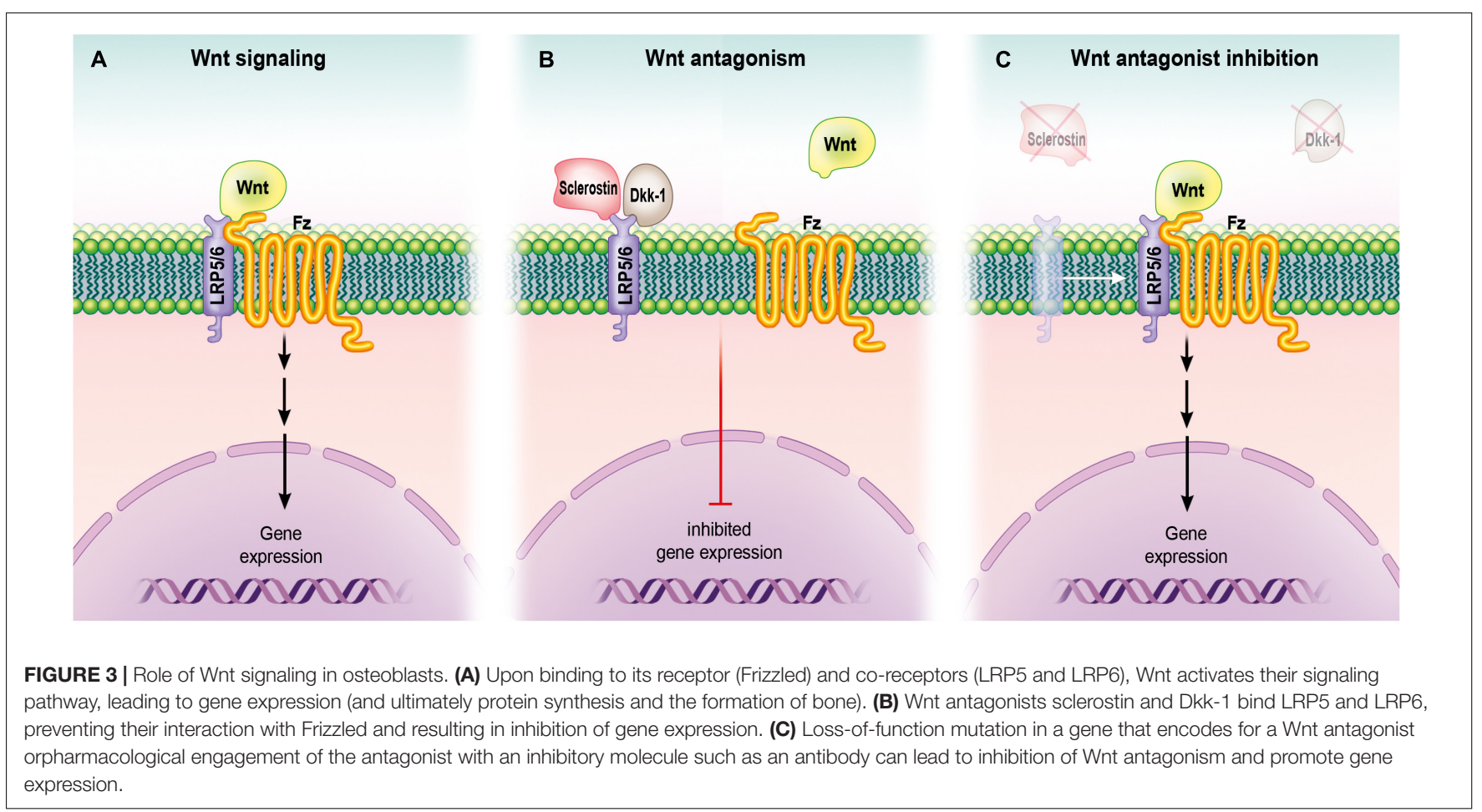


totally understood, it is evident that Wnt signaling regulates the osteogenic differentiation of MSCs (Zhang et al., 2013).

Bone morphogenic proteins (BMPs), mainly BMPs 2, 6, and 9, are potent growth factors which stimulate MSCs to undergo differentiation into osteocytes (Scarfi, 2016). There is substantial crosstalk between BMP and Wnt signaling (Lin and Hankenson, 2011); different BMPs either enhance or antagonize Wnt-induced osteogenic differentiation (Itasaki and Hoppler, 2016; Wu et al., 2016), BMP-induced osteogenic differentiation of MSCs is dependent upon functional Wnt signaling (Tang et al., 2009), and the Wnt and BMP pathways share common targets, such as the connective growth tissue factor (Luo et al., 2004; Si et al., 2006). The osteogenic effects of BMP9 are enhanced by Wnt-3a and inhibited by $\beta$-catenin knockdown or overexpression of FrzB, which is a Fzd antagonist (Boland et al., 2004). The ability of BMP2 to induce ectopic bone formation is antagonized by Dkk-1 overexpression or conditional knockout of $\beta$-catenin (Chen et al., 2007). BMP2 is thought to promote osteogenic differentiation by increasing the expression of LRP5 and stabilizing $\beta$-catenin through the downregulation of $\beta$-Trcp (Zhang et al., 2009).

Overall, the Wnt and additional signaling pathways interact in an extensive network during osteogenic differentiation regulated by a variety of molecules. Full characterization of all these interactions is yet to be completed. Nevertheless, a better understanding of the intricate trans-pathway crosstalk in osteogenesis is a necessity in order to develop new therapies able to act on these signaling pathways for clinical benefit.

\section{OPPORTUNITIES FOR THERAPEUTIC USE}

The ability to control the self-renewal, proliferation, and differentiation of skeletal stem cells could lead to the possibility of expanding a small population of adult progenitor cells and inducing their differentiation in a time sensitive manner to replenish the function of skeletal and cartilaginous tissue (Kodaka et al., 2017). Bone regeneration for fracture repair and defect healing has been a focus of orthopedic surgery (Arvidson et al., 2011). Internal and external fixation at orthotopic sites is the standard of care and achieves short-term stabilization, however, successful long-term stability still requires bone fusion or bone augmentation (Geisler, 2013). Autogenous bone grafting is a common technique to repair large-sized skeletal defects (Oryan et al., 2014), but donor bone is limited in supply and harvesting can cause significant morbidity at the donor site. Additionally transplanted grafts are at risk of infection and failure. Allograft bone may be antigenic and comes with the risk of transmitting disease (Ishikawa et al., 2010), and biomaterials increase the rate of infection and often have suboptimal biomechanical properties (Amini et al., 2012). A cost-effective pharmacologic agent that can be delivered non-invasively is the ideal therapeutic way to promote bone repair and regeneration (Zhang et al., 2016a). Factors BMP-7 (or 'osteogenic protein 1,' OP-1) and BMP-2 have been used with increasing success in preclinical and clinical trials (Roberts and Rosenbaum, 2012). Supplementation with these BMPs enhances bone formation, however, they are effective only in excessive quantities and have short half-lives and thus short-term bioavailability. Additionally, there are currently no methods currently able to deliver these proteins allowing their sustained release, and this has hindered progress to the use of BMPs in humans (Chen, 2001).

The Wnt pathway is well-characterized and is thus an attractive therapeutic for bone repair and skeletal homeostasis (Leucht and Helms, 2015; Gomes et al., 2017). Additionally, a substantial body of literature has accumulated supporting the role of Wnt signaling in skeletogenesis and the regulatory functions of Wnt signaling on stem and skeletal cells (Li et al., 2015). Animal models of osteoarthritis have implicated Wnt/ $\beta$-catenin signaling abnormalities in the changes observed in the cartilage and the bone, and this suggests that the $\beta$-catenin pathway may be a therapeutic target for osteoarthritis (Kim et al., 2013). Sclerostin, a SOST gene product expressed by articular chondrocytes and osteocytes, and inhibits Wnt signaling (Lewiecki, 2014). Sclerosteosis and van Buchem disease are rare genetic disorders with low levels of sclerostin and high BMD. Research in animals suggests that sclerostin may be a potential target for the treatment of conditions of characterized by low BMD and increased risk of fractures, such as osteoporosis (Krishnan et al., 2006; Pietrzyk et al., 2017), and sclerostin is being investigated as a treatment for post-menopausal osteoporosis (Lewiecki, 2011). Production of highly specific antibodies to inhibit a ligand or receptor may help to develop effective therapies that are affordable and can thus become widely used products Humanized sclerostin monoclonal antibodies currently being developed include Romosozumab (AMG 785, CDP-7851; co-developed by Amgen, Thousand Oaks, CA, United States, and UCB, Belgium) and Blosozumab (Eli Lilly and Company, Indianapolis, IN, United States). BPS804 (Novartis, Basel, Switzerland), an antisclerostin agent. The interactions between Wnt receptors and co-receptors also represent reasonable therapeutic targets (MacDonald and $\mathrm{He}$, 2012). Dual inhibition of Wnt via the antagonist DKK-1 in animals treated with sclerostin antibody, results in synergistic bone formation in rodents and non-human primates, suggesting that a negative feedback mechanism limits Wnt-driven bone formation (Florio et al., 2016).

Although there are multiple potential benefits of manipulating the Wnt signaling cascade, these should be performed with caution. The Wnt signaling cascade regulates numerous pathological processes, including the development of cancer (Van Camp et al., 2014). The transportation of Wnt proteins to the target is still challenging, since they are hydrophobic and therefore insoluble in aqueous substances. However, Wnt has successfully been purified and packaged into liposomes, circumventing this delivery challenge (Minear et al., 2010). Incubation of L-Wnt3a can further enhance the survival, proliferation, and engraftment efficiency of bone marrow cells, partly by blocking caspase-dependent programmed cell death (Dhamdhere et al., 2014). Besides, other molecules intervening on different components of the canonical Wnt signaling pathway may offer therapeutic potential (Wagner et al., 2011; Zimmerman et al., 2012). One of these is Lithium, which inhibits GSK3 and can thereby increase $\beta$-catenin, with promising effects on bone 
healing (Freland and Beaulieu, 2012). Further investigation may reveal additional molecules able to potentiate the bone-healing effects of the Wnt signaling pathway.

\section{CONCLUSION AND FUTURE DIRECTIONS}

Wnt signaling during bone regeneration and repair involves a well-organized interaction among various cells and regulatory factors. The ability of adult bone to scarlessly regenerate can be impaired resulting in pathological fractures that become fibrous or fail to unite. The therapeutics developed to promote bone regeneration have focused on stimulating MSCs and their osteogenic differentiation. It is increasingly apparent that Wnt signaling plays a fundamental role during the embryological development of bone and cartilage and, in the adult skeleton, regulates bone homeostasis, repair, and regeneration. The Wnt pathways influence stem cell proliferation, differentiation, and maintenance. Mutations in Wnt genes, receptors, and inhibitors can have detrimental effects on bone formation and turnover, and can result in skeletal abnormalities. Recent progress in understanding the

\section{REFERENCES}

Amini, A. R., Laurencin, C. T., and Nukavarapu, S. P. (2012). Bone tissue engineering: recent advances and challenges. Crit. Rev. Biomed. Eng. 40, 363-408. doi: 10.1615/CritRevBiomedEng.v40.i5.10

Arnsdorf, E. J., Tummala, P., and Jacobs, C. R. (2009). Non-canonical Wnt signaling and $\mathrm{N}$-cadherin related beta-catenin signaling play a role in mechanically induced osteogenic cell fate. PLoS One 4:e5388. doi: 10.1371/ journal.pone.0005388

Arvidson, K., Abdallah, B. M., Applegate, L. A., Baldini, N., Cenni, E., GomezBarrena, E., et al. (2011). Bone regeneration and stem cells. J. Cell. Mol. Med. 15, 718-746. doi: 10.1111/j.1582-4934.2010.01224.x

Balemans, W., and Van Hul, W. (2007). The genetics of low-density lipoprotein receptor-related protein 5 in bone: a story of extremes. Endocrinology 148, 2622-2629. doi: 10.1210/en.2006-1352

Bao, Q., Chen, S., Qin, H., Feng, J., Liu, H., Liu, D., et al. (2017). An appropriate $\mathrm{Wnt} /$ beta-catenin expression level during the remodeling phase is required for improved bone fracture healing in mice. Sci. Rep. 7:2695. doi: 10.1038/s41598017-02705-0

Baron, R., and Kneissel, M. (2013). WNT signaling in bone homeostasis and disease: from human mutations to treatments. Nat. Med. 19, 179-192. doi: $10.1038 / \mathrm{nm} .3074$

Baum, R., and Gravallese, E. M. (2014). Impact of inflammation on the osteoblast in rheumatic diseases. Curr. Osteoporos. Rep. 12, 9-16. doi: 10.1007/s11914-0130183-y

Beederman, M., Lamplot, J. D., Nan, G., Wang, J., Liu, X., Yin, L., et al. (2013). BMP signaling in mesenchymal stem cell differentiation and bone formation. J. Biomed. Sci. Eng. 6, 32-52. doi: 10.4236/jbise.2013.68A 1004

Bianco, P., and Robey, P. G. (2015). Skeletal stem cells. Development 142, 1023-1027. doi: 10.1242/dev.102210

Boland, G. M., Perkins, G., Hall, D. J., and Tuan, R. S. (2004). Wnt 3a promotes proliferation and suppresses osteogenic differentiation of adult human mesenchymal stem cells. J. Cell. Biochem. 93, 1210-1230. doi: 10.1002/ jcb. 20284

Cadigan, K. M., and Waterman, M. L. (2012). TCF/LEFs and Wnt signaling in the nucleus. Cold Spring Harb. Perspect. Biol. 4:a007906. doi: 10.1101/cshperspect. a007906 critical roles of $\mathrm{Wnt} / \beta$-catenin signaling in the development and maturation of skeletal cells has invited opportunities to develop pharmaceutical agents to treat non-unions and accelerate fracture repair. Despite the rapid and measurable accomplishments, the role of the Wnts and Wnt antagonists on skeletal physiology and regeneration remain to be fully elucidated. Clinical trials are currently being undertaken to explore the effects of therapeutic agents manipulating the Wnt signaling pathway on a number of endocrine and orthopedic conditions.

\section{AUTHOR CONTRIBUTIONS}

$\mathrm{KSH}$ conceived of the article and the authors KSH, CT, MRB, DP, DD, ZNM, MPC, JL, KH, CW, SR, DP, GR, GG, SM, MD, JMW, JYC, FS, ML, and $\mathrm{BB}$ made equal contributions to its written content.

\section{ACKNOWLEDGMENTS}

We acknowledge support by the DFG Open Access Publication Funds of the Ruhr-Universität Bochum.

Cao, J., Wei, Y., Lian, J., Yang, L., Zhang, X., Xie, J., et al. (2017). Notch signaling pathway promotes osteogenic differentiation of mesenchymal stem cells by enhancing BMP9/Smad signaling. Int. J. Mol. Med. 40, 378-388. doi: 10.3892/ ijmm.2017.3037

Case, N., and Rubin, J. (2010). Beta-catenin-a supporting role in the skeleton. J. Cell. Biochem. 110, 545-553. doi: 10.1002/jcb.22574

Chanda, D., Kumar, S., and Ponnazhagan, S. (2010). Therapeutic potential of adult bone marrow-derived mesenchymal stem cells in diseases of the skeleton. J. Cell. Biochem. 111, 249-257. doi: 10.1002/jcb.22701

Chen, C., Zhao, M., Tian, A., Zhang, X., Yao, Z., and Ma, X. (2015). Aberrant activation of Wnt/beta-catenin signaling drives proliferation of bone sarcoma cells. Oncotarget 6, 17570-17583.

Chen, Y. (2001). Orthopedic applications of gene therapy. J. Orthop. Sci. 6, 199-207. doi: 10.1007/s007760100072

Chen, Y., Whetstone, H. C., Youn, A., Nadesan, P., Chow, E. C., Lin, A. C., et al. (2007). Beta-catenin signaling pathway is crucial for bone morphogenetic protein 2 to induce new bone formation. J. Biol. Chem. 282, 526-533. doi: 10.1074/jbc.M602700200

Ching, W., and Nusse, R. (2006). A dedicated Wnt secretion factor. Cell 125, 432-433. doi: 10.1016/j.cell.2006.04.018

Clevers, H. (2006). Wnt/beta-catenin signaling in development and disease. Cell 127, 469-480. doi: 10.1016/j.cell.2006.10.018

Colnot, C., Thompson, Z., Miclau, T., Werb, Z., and Helms, J. A. (2003). Altered fracture repair in the absence of MMP9. Development 130, 4123-4133. doi: 10.1242/dev.00559

Crane, J. L., and Cao, X. (2014). Bone marrow mesenchymal stem cells and TGFbeta signaling in bone remodeling. J. Clin. Invest. 124, 466-472. doi: 10.1172/ JCI70050

Cui, Y., Niziolek, P. J., MacDonald, B. T., Zylstra, C. R., Alenina, N., Robinson, D. R., et al. (2011). Lrp5 functions in bone to regulate bone mass. Nat. Med. 17, 684-691. doi: 10.1038/nm.2388

Dhamdhere, G. R., Fang, M. Y., Jiang, J., Lee, K., Cheng, D., Olveda, R. C., et al. (2014). Drugging a stem cell compartment using Wnt3a protein as a therapeutic. PLoS One 9:e83650. doi: 10.1371/journal.pone.008 3650

Diarra, D., Stolina, M., Polzer, K., Zwerina, J., Ominsky, M. S., Dwyer, D., et al. (2007). Dickkopf-1 is a master regulator of joint remodeling. Nat. Med. 13, 156-163. doi: $10.1038 / \mathrm{nm} 1538$ 
Enzo, M. V., Rastrelli, M., Rossi, C. R., Hladnik, U., and Segat, D. (2015). The Wnt/beta-catenin pathway in human fibrotic-like diseases and its eligibility as a therapeutic target. Mol. Cell. Ther. 3:1. doi: 10.1186/s40591-0150038-2

Feng, X., and McDonald, J. M. (2011). Disorders of bone remodeling. Annu. Rev. Pathol. 6, 121-145. doi: 10.1146/annurev-pathol-011110-130203

Ferguson, C., Alpern, E., Miclau, T., and Helms, J. A. (1999). Does adult fracture repair recapitulate embryonic skeletal formation? Mech. Dev. 87, 57-66.

Florio, M., Gunasekaran, K., Stolina, M., Li, X., Liu, L., Tipton, B., et al. (2016). A bispecific antibody targeting sclerostin and DKK-1 promotes bone mass accrual and fracture repair. Nat. Commun. 7:11505. doi: 10.1038/ncomms11505

Freidenstein, A. (1990). "Osteogenic stem cells in bone marrow," in Bone and Mineral Research, eds J. N. M. Heersche and J. A. Kanis (Amsterdam: Elsevier Science Publishers), 243-272.

Freland, L., and Beaulieu, J. M. (2012). Inhibition of GSK3 by lithium, from single molecules to signaling networks. Front. Mol. Neurosci. 5:14. doi: 10.3389/fnmol. 2012.00014

Friedenstein, A., Chailakhjan, R., and Lalykina, K. (1970). The development of fibroblast colonies in monolayer cultures of guinea-pig bone marrow and spleen cells. Cell Prolif. 3, 393-403. doi: 10.1111/j.1365-2184.1970.tb00347.x

Gadjanski, I., Spiller, K., and Vunjak-Novakovic, G. (2012). Time-dependent processes in stem cell-based tissue engineering of articular cartilage. Stem Cell Rev. 8, 863-881. doi: 10.1007/s12015-011-9328-5

Gao, C., Xiao, G., and Hu, J. (2014). Regulation of Wnt/beta-catenin signaling by posttranslational modifications. Cell Biosci. 4:13. doi: 10.1186/2045-3701-4-13

Geetha-Loganathan, P., Nimmagadda, S., and Scaal, M. (2008). Wnt signaling in limb organogenesis. Organogenesis 4, 109-115. doi: 10.4161/org.4.2.5857

Geisler, F. (2013). Stabilization of the sacroiliac joint with the SI-bone surgical technique. Neurosurg. Focus 35(Suppl. 2):Video8. doi: 10.3171/2013.V2. FOCUS13195

Gianakos, A. L., Moya-Angeler, J., Duggal, S., Zambrana, L., Fields, K. G., Mintz, D. N., et al. (2016). The efficacy of bisphosphonates with core decompression and mesenchymal stem cells compared with bisphosphonates alone in the treatment of osteonecrosis of the hip: a retrospective study. HSS J. 12, 137-144. doi: 10.1007/s11420-016-9487-7

Gibon, E., Yao, Z., Rao, A. J., Zwingenberger, S., Batke, B., Valladares, R., et al. (2012). Effect of a CCR1 receptor antagonist on systemic trafficking of MSCs and polyethylene particle-associated bone loss. Biomaterials 33, 3632-3638. doi: 10.1016/j.biomaterials.2012.02.003

Gjerde, C., Mustafa, K., Hellem, S., Rojewski, M., Gjengedal, H., Yassin, M. A., et al. (2018). Cell therapy induced regeneration of severely atrophied mandibular bone in a clinical trial. Stem Cell Res. Ther. 9:213. doi: 10.1186/s13287-0180951-9

Gomes, K. D. N., Alves, A., Dutra, P. G. P., and Viana, G. S. B. (2017). Doxycycline induces bone repair and changes in Wnt signalling. Int. J. Oral Sci. 9, 158-166. doi: 10.1038/ijos.2017.28

Gonzalez-Sancho, J. M., Brennan, K. R., Castelo-Soccio, L. A., and Brown, A. M. (2004). Wnt proteins induce dishevelled phosphorylation via an LRP5/6independent mechanism, irrespective of their ability to stabilize beta-catenin. Mol. Cell. Biol. 24, 4757-4768. doi: 10.1128/MCB.24.11.4757-4768.2004

Granero-Moltó, F., Weis, J. A., Miga, M. I., Landis, B., Myers, T. J., O’Rear, L., et al. (2009). Regenerative effects of transplanted mesenchymal stem cells in fracture healing. Stem Cells 27, 1887-1898. doi: 10.1002/stem.103

Habas, R., and Dawid, I. B. (2005). Dishevelled and Wnt signaling: is the nucleus the final frontier? J. Biol. 4:2.

Heilmann, A., Schinke, T., Bindl, R., Wehner, T., Rapp, A., Haffner-Luntzer, M., et al. (2013). The Wnt serpentine receptor Frizzled-9 regulates new bone formation in fracture healing. PLoS One 8:e84232. doi: 10.1371/journal.pone. 0084232

Herr, P., and Basler, K. (2012). Porcupine-mediated lipidation is required for Wnt recognition by Wls. Dev. Biol. 361, 392-402. doi: 10.1016/j.ydbio.2011. 11.003

Hoang-Kim, A., Gelsomini, L., Luciani, D., Moroni, A., and Giannini, S. (2009). Fracture healing and drug therapies in osteoporosis. Clin. Cases Miner. Bone Metab. 6, 136-143.

Houschyar, K. S., Momeni, A., Pyles, M. N., Maan, Z. N., Whittam, A. J., and Siemers, F. (2015). Wnt signaling induces epithelial differentiation during cutaneous wound healing. Organogenesis 11, 95-104. doi: 10.1080/15476278. 2015.1086052

Huang, H. C., and Klein, P. S. (2004). The Frizzled family: receptors for multiple signal transduction pathways. Genome Biol. 5:234.

Huang, W., Yang, S., Shao, J., and Li, Y. P. (2007). Signaling and transcriptional regulation in osteoblast commitment and differentiation. Front. Biosci. 12, 3068-3092. doi: 10.2741/2296

Ingber, D. E., and Levin, M. (2007). What lies at the interface of regenerative medicine and developmental biology? Development 134, 2541-2547.

Ishikawa, T., Salama, M., Funato, A., Kitajima, H., Moroi, H., Salama, H., et al. (2010). Three-dimensional bone and soft tissue requirements for optimizing esthetic results in compromised cases with multiple implants. Int. J. Periodontics Restorative Dent. 30, 503-511.

Itasaki, N., and Hoppler, S. (2016). Crosstalk between Wnt and bone morphogenic protein signaling: a turbulent relationship. Dev. Dyn. 239, 16-33. doi: 10.1002/ dvdy. 22009

James, A. W. (2013). Review of signaling pathways governing MSC osteogenic and adipogenic differentiation. Scientifica 2013:684736. doi: 10.1155/2013/684736

Kamiya, N., Ye, L., Kobayashi, T., Mochida, Y., Yamauchi, M., Kronenberg, H. M., et al. (2008). BMP signaling negatively regulates bone mass through sclerostin by inhibiting the canonical Wnt pathway. Development 135, 3801-3811. doi: 10.1242/dev.025825

Kang, H., and Hata, A. (2015). The role of microRNAs in cell fate determination of mesenchymal stem cells: balancing adipogenesis and osteogenesis. BMB Rep. 48, 319-323. doi: 10.5483/BMBRep.2015.48.6.206

Kang, S., Bennett, C. N., Gerin, I., Rapp, L. A., Hankenson, K. D., and Macdougald, O. A. (2007). Wnt signaling stimulates osteoblastogenesis of mesenchymal precursors by suppressing CCAAT/enhancer-binding protein alpha and peroxisome proliferator-activated receptor gamma. J. Biol. Chem. 282, 14515-14524. doi: 10.1074/jbc.M700030200

Kestler, H. A., and Kuhl, M. (2008). From individual Wnt pathways towards a Wnt signalling network. Philos. Trans. R. Soc. Lond. B Biol. Sci. 363, 1333-1347. doi: 10.1098/rstb.2007.2251

Kim, J. H., Liu, X., Wang, J., Chen, X., Zhang, H., Kim, S. H., et al. (2013). Wnt signaling in bone formation and its therapeutic potential for bone diseases. Ther. Adv. Musculoskelet. Dis. 5, 13-31. doi: 10.1177/1759720X12466608

Klimczak, A., and Kozlowska, U. (2016). Mesenchymal stromal cells and tissuespecific progenitor cells: their role in tissue homeostasis. Stem Cells Int. 2016:4285215. doi: 10.1155/2016/4285215

Kloen, P., Buijze, G. A., and Ring, D. (2012). Management of forearm nonunions: current concepts. Strategies Trauma Limb Reconstr. 7, 1-11. doi: 10.1007/ s11751-011-0125-0

Kodaka, Y., Rabu, G., and Asakura, A. (2017). Skeletal muscle cell induction from pluripotent stem cells. Stem Cells Int. 2017:1376151. doi: 10.1155/2017/137 6151

Komatsu, D. E., Mary, M. N., Schroeder, R. J., Robling, A. G., Turner, C. H., and Warden, S. J. (2010). Modulation of Wnt signaling influences fracture repair. J. Orthop. Res. 28, 928-936. doi: 10.1002/jor.21078

Komiya, Y., and Habas, R. (2008). Wnt signal transduction pathways. Organogenesis 4, 68-75. doi: 10.4161/org.4.2.5851

Krishnan, V., Bryant, H. U., and Macdougald, O. A. (2006). Regulation of bone mass by Wnt signaling. J. Clin. Invest. 116, 1202-1209. doi: 10.1172/JCI28551

Kureel, J., John, A. A., Prakash, R., and Singh, D. (2018). MiR 376c inhibits osteoblastogenesis by targeting Wnt3 and ARF-GEF-1 -facilitated augmentation of beta-catenin transactivation. J. Cell. Biochem. 119, 3293-3303. doi: $10.1002 /$ jcb. 26490

Leucht, P., and Helms, J. A. (2015). Wnt signaling: an emerging target for bone regeneration. J. Am. Acad. Orthop. Surg. 23, 67-68. doi: 10.5435/JAAOS-2301-67

Lewiecki, E. M. (2011). New targets for intervention in the treatment of postmenopausal osteoporosis. Nat. Rev. Rheumatol. 7, 631-638. doi: 10.1038/ nrrheum.2011.130

Lewiecki, E. M. (2014). Role of sclerostin in bone and cartilage and its potential as a therapeutic target in bone diseases. Ther. Adv. Musculoskelet. Dis. 6, 48-57. doi: 10.1177/1759720X13510479

Li, D., Zhou, J., Chowdhury, F., Cheng, J., Wang, N., and Wang, F. (2011). Role of mechanical factors in fate decisions of stem cells. Regen. Med. 6, 229-240. doi: $10.2217 /$ rme.11.2 
Li, J., Zhang, Y., Zhao, Q., Wang, J., and He, X. (2015). MicroRNA-10a influences osteoblast differentiation and angiogenesis by regulating betacatenin expression. Cell. Physiol. Biochem. 37, 2194-2208. doi: 10.1159/ 000438576

Liang, W. C., Fu, W. M., Wang, Y. B., Sun, Y. X., Xu, L. L., Wong, C. W., et al. (2016). H19 activates Wnt signaling and promotes osteoblast differentiation by functioning as a competing endogenous RNA. Sci. Rep. 6:20121. doi: 10.1038/ srep20121

Lieberman, J. R., Daluiski, A., and Einhorn, T. A. (2002). The role of growth factors in the repair of bone. Biology and clinical applications. J. Bone Joint Surg. Am. 84-A, 1032-1044. doi: 10.2106/00004623-200206000-00022

Lin, G. L., and Hankenson, K. D. (2011). Integration of BMP, Wnt, and notch signaling pathways in osteoblast differentiation. J. Cell. Biochem. 112, 3491-3501. doi: $10.1002 /$ jcb.23287

Liu, Z., Tang, Y., Qiu, T., Cao, X., and Clemens, T. L. (2006). A dishevelled-1/Smad1 interaction couples WNT and bone morphogenetic protein signaling pathways in uncommitted bone marrow stromal cells. J. Biol. Chem. 281, 17156-17163. doi: $10.1074 /$ jbc.M513812200

Long, F., and Ornitz, D. M. (2013). Development of the endochondral skeleton. Cold Spring Harb. Perspect. Biol. 5:a008334. doi: 10.1101/cshperspect.a008334

Lu, D., and Carson, D. A. (2009). Spiperone enhances intracellular calcium level and inhibits the Wnt signaling pathway. BMC Pharmacol. 9:13. doi: 10.1186/ 1471-2210-9-13

Luo, Q., Kang, Q., Si, W., Jiang, W., Park, J. K., Peng, Y., et al. (2004). Connective tissue growth factor (CTGF) is regulated by Wnt and bone morphogenetic proteins signaling in osteoblast differentiation of mesenchymal stem cells. J. Biol. Chem. 279, 55958-55968. doi: 10.1074/jbc.M407810200

Ma, B., and Hottiger, M. O. (2016). Crosstalk between Wnt/beta-Catenin and NF-kappaB signaling pathway during inflammation. Front. Immunol. 7:378. doi: $10.3389 /$ fimmu.2016.00378

MacDonald, B. T., and He, X. (2012). Frizzled and LRP5/6 receptors for Wnt/betacatenin signaling. Cold Spring Harb. Perspect. Biol. 4:a007880. doi: 10.1101/ cshperspect.a007880

MacDonald, B. T., Tamai, K., and He, X. (2009). Wnt/beta-catenin signaling: components, mechanisms, and diseases. Dev. Cell 17, 9-26. doi: 10.1016/j. devcel.2009.06.016

Marsell, R., and Einhorn, T. A. (2011). The biology of fracture healing. Injury 42, 551-555. doi: 10.1016/j.injury.2011.03.031

Maupin, K. A., Droscha, C. J., and Williams, B. O. (2013). A comprehensive overview of skeletal phenotypes associated with alterations in Wnt/beta-catenin signaling in humans and mice. Bone Res. 1, 27-71. doi: 10.4248/BR201301004

Medina, M., and Wandosell, F. (2011). Deconstructing GSK-3: the fine regulation of its activity. Int. J. Alzheimers Dis. 2011:479249. doi: 10.4061/2011/479249

Mikels, A. J., and Nusse, R. (2006). Wnts as ligands: processing, secretion and reception. Oncogene 25, 7461-7468. doi: 10.1038/sj.onc. 1210053

Minear, S., Leucht, P., Jiang, J., Liu, B., Zeng, A., Fuerer, C., et al. (2010). Wnt proteins promote bone regeneration. Sci. Transl. Med. 2:29ra30. doi: 10.1126/ scitranslmed.3000231

Mohammed, M. K., Shao, C., Wang, J., Wei, Q., Wang, X., Collier, Z., et al. (2016). Wnt/beta-catenin signaling plays an ever-expanding role in stem cell self-renewal, tumorigenesis and cancer chemoresistance. Genes Dis. 3, 11-40. doi: 10.1016/j.gendis.2015.12.004

Morgan, E. F., De Giacomo, A., and Gerstenfeld, L. C. (2014). Overview of skeletal repair (fracture healing and its assessment). Methods Mol. Biol. 1130, 13-31. doi: 10.1007/978-1-62703-989-5_2

Nemoto, E., Ebe, Y., Kanaya, S., Tsuchiya, M., Nakamura, T., Tamura, M., et al. (2012). Wnt5a signaling is a substantial constituent in bone morphogenetic protein-2-mediated osteoblastogenesis. Biochem. Biophys. Res. Commun. 422, 627-632. doi: 10.1016/j.bbrc.2012.05.039

Oryan, A., Alidadi, S., Moshiri, A., and Maffulli, N. (2014). Bone regenerative medicine: classic options, novel strategies, and future directions. J. Orthop. Surg. Res. 9:18. doi: 10.1186/1749-799X-9-18

Oryan, A., Monazzah, S., and Bigham-Sadegh, A. (2015). Bone injury and fracture healing biology. Biomed. Environ. Sci. 28, 57-71.

Ozcivici, E., Luu, Y. K., Adler, B., Qin, Y. X., Rubin, J., Judex, S., et al. (2010). Mechanical signals as anabolic agents in bone. Nat. Rev. Rheumatol. 6, 50-59. doi: 10.1038/nrrheum.2009.239
Pajarinen, J., Lin, T. H., Nabeshima, A., Jämsen, E., Lu, L., Nathan, K., et al. (2017). Mesenchymal stem cells in the aseptic loosening of total joint replacements. J. Biomed. Mater. Res. A 105, 1195-1207. doi: 10.1002/jbm.a.35978

Panteli, M., Pountos, I., Jones, E., and Giannoudis, P. V. (2015). Biological and molecular profile of fracture non-union tissue: current insights. J. Cell. Mol. Med. 19, 685-713. doi: 10.1111/jcmm.12532

Peng, S., Gao, D., Gao, C., Wei, P., Niu, M., and Shuai, C. (2016). MicroRNAs regulate signaling pathways in osteogenic differentiation of mesenchymal stem cells (Review). Mol. Med. Rep. 14, 623-629. doi: 10.3892/mmr.2016.5335

Pesce, V., Speciale, D., Sammarco, G., Patella, S., Spinarelli, A., and Patella, V. (2009). Surgical approach to bone healing in osteoporosis. Clin. Cases Miner. Bone Metab. 6, 131-135.

Pietrzyk, B., Smertka, M., and Chudek, J. (2017). Sclerostin: intracellular mechanisms of action and its role in the pathogenesis of skeletal and vascular disorders. Adv. Clin. Exp. Med. 26, 1283-1291. doi: 10.17219/acem/ 68739

Pinzone, J. J., Hall, B. M., Thudi, N. K., Vonau, M., Qiang, Y. W., Rosol, T. J., et al. (2009). The role of Dickkopf-1 in bone development, homeostasis, and disease. Blood 113, 517-525. doi: 10.1182/blood-2008-03-145169

Rahman, M. S., Akhtar, N., Jamil, H. M., Banik, R. S., and Asaduzzaman, S. M. (2015). TGF-beta/BMP signaling and other molecular events: regulation of osteoblastogenesis and bone formation. Bone Res. 3:15005. doi: 10.1038/ boneres. 2015.5

Regard, J. B., Zhong, Z., Williams, B. O., and Yang, Y. (2012). Wnt signaling in bone development and disease: making stronger bone with Wnts. Cold Spring Harb. Perspect. Biol. 4:a007997. doi: 10.1101/cshperspect.a007997

Reischl, S., Vanselow, K., Westermark, P. O., Thierfelder, N., Maier, B., Herzel, H., et al. (2007). Beta-TrCP1-mediated degradation of PERIOD2 is essential for circadian dynamics. J. Biol. Rhythms 22, 375-386. doi: 10.1177/ 0748730407303926

Rivas, R., and Shapiro, F. (2002). Structural stages in the development of the long bones and epiphyses: a study in the New Zealand white rabbit. J. Bone Joint Surg. Am. 84-A, 85-100. doi: 10.2106/00004623-200201000-00013

Roberts, T. T., and Rosenbaum, A. J. (2012). Bone grafts, bone substitutes and orthobiologics: the bridge between basic science and clinical advancements in fracture healing. Organogenesis 8, 114-124. doi: 10.4161/org.23306

Rosen, E. Y., Wexler, E. M., Versano, R., Coppola, G., Gao, F., Winden, K. D., et al. (2011). Functional genomic analyses identify pathways dysregulated by progranulin deficiency, implicating Wnt signaling. Neuron 71, 1030-1042. doi: 10.1016/j.neuron.2011.07.021

Scarfi, S. (2016). Use of bone morphogenetic proteins in mesenchymal stem cell stimulation of cartilage and bone repair. World J. Stem Cells 8, 1-12. doi: 10.4252/wjsc.v8.i1.1

Schulze, J., Seitz, S., Saito, H., Schneebauer, M., Marshall, R. P., Baranowsky, A., et al. (2010). Negative regulation of bone formation by the transmembrane Wnt antagonist Kremen-2. PLoS One 5:e10309. doi: 10.1371/journal.pone.0010309

Secreto, F. J., Hoeppner, L. H., and Westendorf, J. J. (2009). Wnt signaling during fracture repair. Curr. Osteoporos. Rep. 7, 64-69. doi: 10.1007/s11914-0090012-5

Sethi, J. K., and Vidal-Puig, A. (2010). Wnt signalling and the control of cellular metabolism. Biochem. J. 427, 1-17. doi: 10.1042/BJ20091866

Shahi, M., Peymani, A., and Sahmani, M. (2017). Regulation of bone metabolism. Rep. Biochem. Mol. Biol. 5, 73-82.

Shevtsov, S. P., Haq, S., and Force, T. (2006). Activation of beta-catenin signaling pathways by classical G-protein-coupled receptors: mechanisms and consequences in cycling and non-cycling cells. Cell Cycle 5, 2295-2300. doi: $10.4161 /$ cc.5.20.3357

Shi, J., Chi, S., Xue, J., Yang, J., Li, F., and Liu, X. (2016). Emerging role and therapeutic implication of Wnt signaling pathways in autoimmune diseases. J. Immunol. Res. 2016:9392132. doi: 10.1155/2016/9392132

Si, W., Kang, Q., Luu, H. H., Park, J. K., Luo, Q., Song, W. X., et al. (2006). CCN1/Cyr61 is regulated by the canonical Wnt signal and plays an important role in Wnt3A-induced osteoblast differentiation of mesenchymal stem cells. Mol. Cell. Biol. 26, 2955-2964. doi: 10.1128/MCB.26.8.2955-2964. 2006

Stamos, J. L., and Weis, W. I. (2013). The beta-catenin destruction complex. Cold Spring Harb. Perspect. Biol. 5:a007898. doi: 10.1101/cshperspect.a007898 
Tamura, M., Nemoto, E., Sato, M. M., Nakashima, A., and Shimauchi, H. (2010). Role of the Wnt signaling pathway in bone and tooth. Front. Biosci. 2, 1405-1413. doi: 10.2741/e201

Tang, N., Song, W. X., Luo, J., Luo, X., Chen, J., Sharff, K. A., et al. (2009). BMP9 -induced osteogenic differentiation of mesenchymal progenitors requires functional canonical Wnt/beta-catenin signalling. J. Cell. Mol. Med. 13, 2448-2464. doi: 10.1111/j.1582-4934.2008.00569.x

Tarantino, U., Cerocchi, I., Scialdoni, A., Saturnino, L., Feola, M., Celi, M., et al. (2011). Bone healing and osteoporosis. Aging Clin. Exp. Res. 23(Suppl. 2), 62-64.

Tarapore, R. S., Siddiqui, I. A., and Mukhtar, H. (2012). Modulation of Wnt/betacatenin signaling pathway by bioactive food components. Carcinogenesis 33, 483-491. doi: 10.1093/carcin/bgr305

Thrasivoulou, C., Millar, M., and Ahmed, A. (2013). Activation of intracellular calcium by multiple Wnt ligands and translocation of beta-catenin into the nucleus: a convergent model of $\mathrm{Wnt} / \mathrm{Ca}^{2+}$ and $\mathrm{Wnt} /$ beta-catenin pathways. J. Biol. Chem. 288, 35651-35659. doi: 10.1074/jbc.M112.43 7913

Topol, L., Jiang, X., Choi, H., Garrett-Beal, L., Carolan, P. J., and Yang, Y. (2003). Wnt-5a inhibits the canonical Wnt pathway by promoting GSK-3-independent beta-catenin degradation. J. Cell. Biol. 162, 899-908. doi: 10.1083/jcb.20030 3158

Ullah, I., Subbarao, R. B., and Rho, G. J. (2015). Human mesenchymal stem cells - current trends and future prospective. Biosci. Rep. 35:e00191. doi: 10.1042/ BSR20150025

Valenta, T., Hausmann, G., and Basler, K. (2012). The many faces and functions of beta-catenin. EMBO J. 31, 2714-2736. doi: 10.1038/emboj.2012.150

van Amerongen, R., and Nusse, R. (2009). Towards an integrated view of Wnt signaling in development. Development 136, 3205-3214. doi: 10.1242/dev. 033910

Van Camp, J. K., Beckers, S., Zegers, D., and Van Hul, W. (2014). Wnt signaling and the control of human stem cell fate. Stem Cell Rev. 10, 207-229. doi: 10.1007/s12015-013-9486-8

Victoria, G., Petrisor, B., Drew, B., and Dick, D. (2009). Bone stimulation for fracture healing: what's all the fuss? Indian J. Orthop. 43, 117-120. doi: 10.4103/ 0019-5413.50844

Vimalraj, S., and Selvamurugan, N. (2013). MicroRNAs: synthesis, gene regulation and osteoblast differentiation. Curr. Issues Mol. Biol. 15, 7-18.

Wagner, E. R., Zhu, G., Zhang, B. Q., Luo, Q., Shi, Q., Huang, E., et al. (2011). The therapeutic potential of the Wnt signaling pathway in bone disorders. Curr. Mol. Pharmacol. 4, 14-25. doi: 10.2174/1874467211104010014

Wang, M., Yuan, Z., Ma, N., Hao, C., Guo, W., Zou, G., et al. (2017). Advances and prospects in stem cells for cartilage regeneration. Stem Cells Int. 2017:4130607. doi: 10.1155/2017/4130607

Wang, T., Zhang, X., and Bikle, D. D. (2017). Osteogenic differentiation of periosteal cells during fracture healing. J. Cell. Physiol. 232, 913-921. doi: 10. $1002 /$ jcp. 25641

Wang, T., and Xu, Z. (2010). miR-27 promotes osteoblast differentiation by modulating Wnt signaling. Biochem. Biophys. Res. Commun. 402, 186-189. doi: 10.1016/j.bbrc.2010.08.031

Wang, Y., Zhou, C. J., and Liu, Y. (2018). Wnt signaling in kidney development and disease. Prog. Mol. Biol. Transl. Sci. 153, 181-207. doi: 10.1016/bs.pmbts. 2017.11.019

Willert, K., and Nusse, R. (2012). Wnt proteins. Cold Spring Harb. Perspect. Biol. 4:a007864. doi: 10.1101/cshperspect.a007864

Wu, M., Chen, G., and Li, Y. P. (2016). TGF-beta and BMP signaling in osteoblast, skeletal development, and bone formation, homeostasis and disease. Bone Res. 4:16009. doi: 10.1038/boneres.2016.9
Wu, M., and Herman, M. A. (2006). A novel noncanonical Wnt pathway is involved in the regulation of the asymmetric B cell division in C. elegans. Dev. Biol. 293, 316-329. doi: 10.1016/j.ydbio.2005.12.024

Wu, S., Zang, W., Li, X., and Sun, H. (2011). Proepithelin stimulates growth plate chondrogenesis via nuclear factor-kappaB-p65-dependent mechanisms. J. Biol. Chem. 286, 24057-24067. doi: 10.1074/jbc.M110.201368

Xu, H., Duan, J., Ning, D., Li, J., Liu, R., Yang, R., et al. (2014). Role of Wnt signaling in fracture healing. BMB Rep. 47, 666-672. doi: 10.5483/BMBRep.2014.47. 12.193

Yavropoulou, M. P., and Yovos, J. G. (2007). The role of the Wnt signaling pathway in osteoblast commitment and differentiation. Hormones 6, 279-294. doi: 10.14310/horm.2002.1111024

Zhan, T., Rindtorff, N., and Boutros, M. (2017). Wnt signaling in cancer. Oncogene 36, 1461-1473. doi: 10.1038/onc.2016.304

Zhang, L., Tang, Y., Zhu, X., Tu, T., Sui, L., Han, Q., et al. (2017). Overexpression of MiR-335-5p promotes bone formation and regeneration in mice. J. Bone Miner. Res. 32, 2466-2475. doi: 10.1002/jbmr.3230

Zhang, M., Yan, Y., Lim, Y. B., Tang, D., Xie, R., Chen, A., et al. (2009). BMP2 modulates beta-catenin signaling through stimulation of Lrp5 expression and inhibition of beta-TrCP expression in osteoblasts. J. Cell. Biochem. 108, 896-905. doi: 10.1002/jcb.22319

Zhang, R., Oyajobi, B. O., Harris, S. E., Chen, D., Tsao, C., Deng, H. W., et al. (2013). Wnt/beta-catenin signaling activates bone morphogenetic protein 2 expression in osteoblasts. Bone 52, 145-156. doi: 10.1016/j.bone.2012.09.029

Zhang, W., Ouyang, H., Dass, C. R., and Xu, J. (2016a). Current research on pharmacologic and regenerative therapies for osteoarthritis. Bone Res. 4:15040. doi: 10.1038/boneres.2015.40

Zhang, W., Xue, D., Yin, H., Wang, S., Li, C., Chen, E., et al. (2016b). Overexpression of HSPA1A enhances the osteogenic differentiation of bone marrow mesenchymal stem cells via activation of the Wnt/beta-catenin signaling pathway. Sci. Rep. 6:27622. doi: 10.1038/srep27622

Zheng, H. F., Tobias, J. H., Duncan, E., Evans, D. M., Eriksson, J., Paternoster, L., et al. (2012). WNT16 influences bone mineral density, cortical bone thickness, bone strength, and osteoporotic fracture risk. PLoS Genet. 8:e1002745. doi: 10.1371/journal.pgen.1002745

Zhong, Z., Ethen, N. J., and Williams, B. O. (2014). WNT signaling in bone development and homeostasis. Wiley Interdiscip. Rev. Dev. Biol. 3, 489-500. doi: 10.1002/wdev.159

Zimmerman, Z. F., Moon, R. T., and Chien, A. J. (2012). Targeting Wnt pathways in disease. Cold Spring Harb. Perspect. Biol. 4:a008086. doi: 10.1101/cshperspect. a008086

Zwingenberger, S., Yao, Z., Jacobi, A., Vater, C., Valladares, R. D., Li, C., et al. (2013). Enhancement of BMP-2 induced bone regeneration by SDF- $1 \alpha$ mediated stem cell recruitment. Tissue Eng. Part A 20, 810-818. doi: 10.1089/ten.TEA.2013. 0222

Conflict of Interest Statement: The authors declare that the research was conducted in the absence of any commercial or financial relationships that could be construed as a potential conflict of interest.

Copyright () 2019 Houschyar, Tapking, Borrelli, Popp, Duscher, Maan, Chelliah, Li, Harati, Wallner, Rein, Pförringer, Reumuth, Grieb, Mouraret, Dadras, Wagner, Cha, Siemers, Lehnhardt and Behr. This is an open-access article distributed under the terms of the Creative Commons Attribution License (CC BY). The use, distribution or reproduction in other forums is permitted, provided the original author(s) and the copyright owner(s) are credited and that the original publication in this journal is cited, in accordance with accepted academic practice. No use, distribution or reproduction is permitted which does not comply with these terms. 